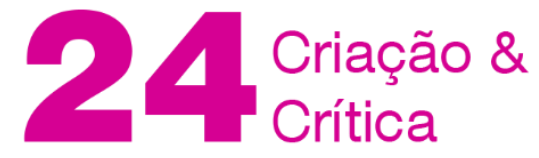

\section{O CASO Bug-JARGal: TRADUÇÃO, TRANSPOSIÇÃo E HIPERTEXTUALIDADE NO ROMANTISMO BRASILEIRO}

\author{
Mateus Roman Pamboukian ${ }^{1}$
}

\begin{abstract}
Resumo: Este artigo pretende discutir derivações textuais do romance de Victor Hugo Bug-Jargal, especialmente as traduções parciais em verso feitas por Gonçalves Dias e Castro Alves. Também é discutida a influência do romance em outros poemas dos dois autores, notadamente "Canção do exílio" (Gonçalves Dias) e "Cachoeira de Paulo Afonso" (Castro Alves). Por fim, discute-se o papel da literatura traduzida na elaboração do repertório poético da literatura brasileira em seus anos de formação. Para tanto, lançamos mão das contribuições teóricas de Gérard Genette, Haroldo de Campos e Itamar Even-Zohar.
\end{abstract}

PALAVRAS-CHAVE: Tradução; Romantismo; Intertextualidade; Literatura francesa; Literatura brasileira.

\section{THE BUG-JARGAL AFFAIR: TRANSLATION, TRANSPOSITION AND HYPERTEXTUALITY IN BRAZILIAN ROMANTICISM}

ABSTRACT: This paper aims at discussing textual derivatives of Victor Hugo's novel Bug-Jargal, especially the partial translations in verse made by Gonçalves Dias and Castro Alves. We also discuss the influence of the novel on other poems of both authors, notably "Canção do exílio" (Gonçalves Dias) and "Cachoeira de Paulo Afonso" (Castro Alves). Finally, we discuss the role of translated literature in the elaboration of the poetic repertoire of Brazilian literature in its formative years. For this purpose, we make use of theoretical contributions from Gérard Genette, Haroldo de Campos and Itamar Even-Zohar.

KEYWORDS: Translation; Romanticism; Intertextuality; French literature; Brazilian literature.

\section{Even-Zohar, Campos e Genette: três abordagens}

Conhecido no campo dos estudos da tradução por sua teoria dos polissistemas, o teórico israelense Itamar Even-Zohar postula que a literatura traduzida pode ocupar quer uma posição periférica, quer uma posição central no seio de um determinado polissistema literário. Interessam-nos particularmente suas considerações a respeito do segundo caso:

Dizer que a literatura traduzida mantém uma posição central no polissistema literário significa que ela participa ativamente na modelagem do centro do polissistema. Em tal situação, ela é geralmente parte integral de forças inovadoras. Como tal, é provável que seja identificada com eventos decisivos na história literária enquanto tais eventos se dão. Isso implica que, nessa

1 USP, Mestre em Estudos Linguísticos, Literários e Tradutológicos em Francês, mateusroman2@gmail.com 


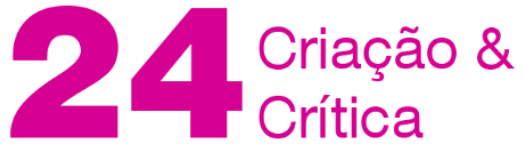

situação, nenhuma distinção clara seja mantida entre escritos "originais" e "traduzidos", e que frequentemente sejam escritores proeminentes (ou membros da vanguarda que estão prestes a se tornar escritores proeminentes) quem produz as traduções mais notáveis e apreciadas. Além disso, num estado tal em que novos modelos literários estejam surgindo, é provável que a tradução se torne um dos meios de elaborar o novo repertório. Através de obras estrangeiras, introduzem-se facetas (tanto princípios quanto elementos) na literatura local que não existiam anteriormente. Isto pode incluir não só novos modelos de realidade a substituir os antigos e estabelecidos que não sejam mais efetivos, mas também toda uma gama de outras facetas, tais quais uma nova linguagem (poética), ou padrões e técnicas composicionais. (EVEN-ZOHAR, 2000, p. 193, tradução nossa $)^{2}$

A diluição da distinção entre produções "originais" e "traduzidas" é pensada sob outras perspectivas por outros teóricos. Entre nós, o primeiro nome a vir à mente talvez seja o de Haroldo de Campos, conhecido por postular uma tradução crítica e criativa, por meio da qual "se desmonta e se remonta a máquina da criação" (CAMPOS, 2006, p.43). À postulação haroldiana da transcriação subjaz sua própria teoria intertextual da literatura como um incessante movimento "plagiotrópico" de derivação textual, no qual tanto produções "originais" ou "traduzidas" se irmanam por seu caráter de "canto paralelo":

A plagiotropia (do gr. plágios, oblíquo; que não é em linha reta; transversal, de lado), tal como a entendi no curso que ministrei na primavera de 1978 na Universidade de Yale sobre a evolução de formas na poesia brasileira, se resolve em tradução da tradição, num sentido não necessariamente retilíneo. [...] Tem a ver, obviamente, com a ideia de paródia como "canto paralelo", generalizando-a para designar o movimento não-linear de transformação dos textos ao longo da história, por derivação nem sempre imediata. Conjuga-se com minha concepção da operação tradutora como o capítulo por excelência de toda possível teoria literária (e literatura comparada nela fundada). Assim, o nosso Gregório de Matos é tradutor (transformador) ostensivo de Góngora e Quevedo, como, de maneira menos explícita, mas num profundo sentido de

2 "To say that translated literature maintains a central position in the literary polysystem means that it participates actively in shaping the center of the polysystem. In such a situation it is by and large an integral part of innovatory forces, and as such likely to be identified with major events in literary history while these are taking place. This implies that in this situation no clear-cut distinction is maintained between 'original' and 'translated' writings, and that often it is the leading writers (or members of the avant-garde who are about to become leading writers) who produce the most conspicuous appreciated translations. Moreover, in such a state when new literary models are emerging, translation is likely to become one of the means of elaborating the new repertoire. Through the foreign works, features (both principles and elements) are introduced into the home literature which did not exist there before. These include possibly not only new models of reality to replace the old and established ones that are no longer effective, but a whole range of other features as well, such as a new (poetic) language, or compositional patterns and techniques". 


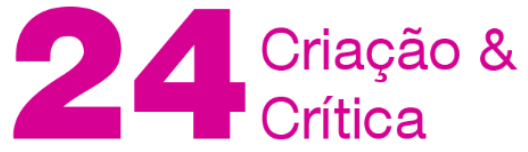

diálogo com as inflexões (tropismos) da tradição, Camões e Shakespeare o são, em português e inglês respectivamente, de certas conquistas da dicção dantesca (CAMPOS, 1981, p.75-76).

Assim, uma vez que se entende a literatura como um todo inserida nesse processo incessante de derivação textual mais ou menos oblíquo, torna-se possível desierarquizar "originais" e "traduções", na medida em que a tradução seria só um dos muitos processos de derivação textual. É mais ou menos nesses termos que Gérard Genette, em sua complexa taxonomia de "hipertextos", enquadra a tradução como uma das diversas formas de derivação por transformação, mais especificamente como um tipo de transposição de uma língua a outra:

A forma de transposição mais chamativa e certamente mais difundida consiste em transpor um texto de uma língua para outra: trata-se, evidentemente, da tradução, cuja importância pouco se pode contestar, seja porque se deve traduzir as obras-primas, seja porque algumas traduções são elas mesmas obras-primas. (GENETTE, 1982, p.293, tradução nossa) ${ }^{3}$

Embora diferentes entre si sob diversos aspectos, é evidente que as três abordagens teóricas compartilham uma certa concepção do texto traduzido menos rígida que a tradicional oposição dicotômica entre "texto original" e "texto traduzido": para Genette, há traduções que podem ser consideradas obras-primas por si mesmas; Even-Zohar aponta que a literatura traduzida frequentemente desempenha papel crucial no desenvolvimento do repertório de um polissistema literário; Campos vê a tradução como "capítulo por excelência de toda possível teoria literária", aproximando-a explicitamente de outras formas de transformação textual. Dessa forma, as convergências entre estes três teóricos nos servirão para pensar um caso exemplar em que as fronteiras entre tradução e criação parecem se dissolver.

\section{Gonçalves Dias e Bug-Jargal}

Escrevendo a respeito do histórico de traduções de Mallarmé no Brasil, Álvaro Faleiros chama a atenção para o que denomina uma "certa prática de traduzir" do fim do século XIX, que assim caracteriza:

a) inclusão de traduções em livros de poemas dos poetas-tradutores; b) adoção da tradução quase como texto próprio pelos tradutores-poetas; c)

3 "La forme de transposition la plus voyante, et à coup sûr la plus répandue, consiste à transposer un texte d'une langue à une autre : c'est évidemment la traduction, dont l'importance littéraire n'est guère contestable, soit parce qu'il faut bien traduire les chefs-d'œuvre, soit parce que certaines traductions sont elles-mêmes des chefs-d'œuvre". 


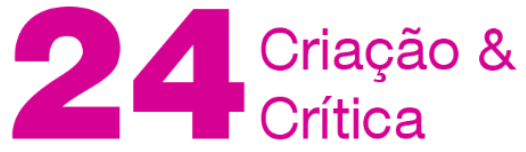

ampla liberdade de intervenção nos textos originais. Essa prática revelaria "um dado próprio do estatuto da tradução até esse período". (FALEIROS, 2012, p. 19)

Exemplo eloquente desse estatuto da tradução está em Últimos Cantos (1851), obra que Gonçalves Dias define como seu "último livro de poesias soltas" (DIAS, 2016, p. 7). Trata-se do poema "Canção de Bug-Jargal", uma tradução em verso de um trecho em prosa de Victor Hugo retirado do romance Bug-Jargal (1826)":

- Pourquoi me fuis-tu, Maria? pourquoi me fuis-tu, jeune fille? pourquoi cette terreur qui glace ton âme quand tu m'entends? je suis en effet bien formidable! je ne sais qu'aimer, souffrir et chanter! [...] (HUGO, 1910, p.392)

Maria, por que me foges?

Por que me foges, donzela?

Minha voz! o que tem ela

Que te faz estremecer;

Tão horrível sou acaso?

Sei amar, cantar, sofrer![...]

(DIAS, 2016, p.184)

Se a tradução pode ser considerada uma tranposição de uma língua para a outra, conforme quer Gérard Genette, o poema de Gonçalves Dias opera pelo menos dois outros tipos de transposição: em primeiro lugar, há o que o próprio Genette (GENETTE, 1982, p.300) denominou "versificação" (versification), a transposição de um texto em prosa para um texto em versos. Em segundo lugar, algo que Genette não chegou a classificar em sua lista de processos de derivação textual por transposição elencados em Palimpsestes, mas que tomamos a liberdade de postular por analogia: a transposição de gênero. $O$ fragmento de romance de Victor Hugo é "promovido" a poema autônomo do tradutor-poeta Gonçalves Dias, que recria o texto sob ampla liberdade de intervenção e o inclui em um livro autoral. Recuperando Even-Zohar, podemos afirmar que se observam aqui duas circunstâncias apontadas pelo teórico israelense como indícios da participação da literatura traduzida nas "forças inovadoras" de um dado polissistema: a) apaga-se a distinção entre literatura 'original' e 'traduzida'; b) a literatura traduzida é produzida por escritores proeminentes. Quanto à hipótese de Even-Zohar segundo a qual "é provável que a tradução [sob tais condições] se torne um dos meios de elaborar o novo repertório" (EVEN-ZOHAR, 2000, p. 193, tradução

4 O romance Bug-Jargal de 1826 foi precedido por uma primeira versão mais enxuta de 1819, que possuía diferenças significativas de trama com relação à versão mais longa que a sucedeu. $O$ trecho da canção do protagonista Bug-Jargal inexiste na primeira versão, bem como a personagem Maria e o triângulo amoroso esboçado entre d'Auvernay, Maria e Bug-Jargal, que parece ter influenciado o triângulo amoroso entre Álvaro, Ceci e Peri n'O Guarani (1857) de José de Alencar. A esse respeito, ver Ribeiro (2003). 


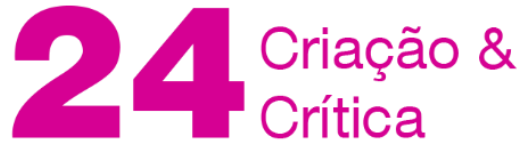

nossa), parece-nos profícuo examinarmos a quarta estrofe da tradução-poema de Gonçalves Dias, cotejada com o fragmento de Hugo que Ihe corresponde:

Hélas ! ta voix est plus douce pour moi que le chant même des jeunes oiseaux qui battent de l'aile dans le ciel, et qui viennent du côté de ma patrie; De ma patrie où j'étais roi, de ma patrie où j'étais libre![...]

(HUGO, 1910, p. 392-393)

Tua voz! eu quero ouvir-t'a

Mais do que as aves cantando,

Que vem da terra voando,

Onde eu a vida provei;

Da terra onde eu era livre,

Da terra onde eu era rei! [...]

(DIAS, 2016, p.184)

Não nos deteremos aqui sobre a forma engenhosa com que o poeta maranhense, sob a contrainte da métrica e da rima, passa longe da tradução verbum pro verbo, reelaborando as sentenças da personagem de Victor Hugo segundo um princípio de paráfrase condensadora. Interessa-nos, sobretudo, chamar a atenção para um elemento que remete a outro texto do mesmo tradutor-poeta: a associação entre o canto da ave e a saudade da terra pátria distante, motivo do mais célebre texto de Gonçalves Dias, que parece tê-lo encontrado neste excerto do romance hugoano. Assim como Goethe acreditava "somente ser possível produzir algo grande mediante a apropriação de tesouros alheios" (Apud CAMPOS, 1981, p.75-76), assim como Pound acreditava que grandes poetas "amontoam todas as coisas excelentes que podem pedir, tomar de empréstimos ou roubar de seus predecessores e contemporâneos" (Apud CAMPOS, 1981, p.76), a arquicélebre "Canção do exílio", que Affonso Romano de Sant'anna acredita ser "o poema mais parafraseado, estilizado e parodiado de nossa literatura" (SANT'ANNA, 1988, p.23), parece se irmanar com "Canção de Bug-Jargal" pela condição de "canto paralelo" de Victor Hugo. Compare-se o texto de Hugo na tradução prosaica de Bezerra de Menezes Neto com a estrofe inicial de "Canção do Exílio":

Ai! a tua voz é mais doce para mim do que o próprio canto das aves que ruflam as asas nos céus, [sic] vindos das bandas da minha pátria![...] (HUGO, 1947, p.30-31)

Minha terra tem palmeiras, Onde canta o Sabiá;

As aves, que aqui gorjeiam, Não gorjeiam como lá. 


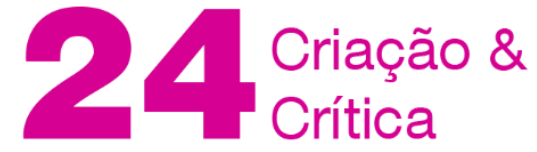

(DIAS, 1998, p. 80)

Frise-se, ainda, que a palmeira, outro índice importante de "Canção do exílio", também aparece mais de uma vez tanto no excerto de Hugo quando na tradução-poema de Gonçalves Dias:

Ô Maria ! tu ressembles au beau palmier, svelte et doucement balancé sur sa tige, et tu te mires dans l'œil de ton jeune amant, comme le palmier dans l'eau transparente de la fontaine. Mais, ne le sais-tu pas ? il y a quelquefois au fond du désert un ouragan jaloux du bonheur de la fontaine aimée; il accourt, et l'air et le sable se mêlent sous le vol de ses lourdes ailes ; il enveloppe l'arbre et la source d'un tourbillon de feu; et la fontaine se dessèche, et le palmier sent se crisper sous l'haleine de mort le cercle vert de ses feuilles, qui avait la majesté d'une couronne et la grâce d'une chevelure. (HUGO, 1910, p. 392393)

És, Maria, qual palmeira, Altiva, esbelta, engraçada, No tronco seu balançada

Por leve brisa fagueira, No teu amante a rever-te, Como na fonte a palmeira.

Mas não sabes? - Do deserto

A tempestade valente

Corre às vezes de repente

Por acabar apressada

Com seu hálito de fogo

A palmeira, a fonte amada![...]

(DIAS, 2016, p.185)

Maria Aparecida Ribeiro (2003) corrobora nossa hipótese de que a leitura de BugJargal, muito antes do poema-tradução incluído em Últimos Cantos (1851), ecoaria já em poemas de Primeiros Cantos (1847). Assim, "Canção do Índio" seria uma espécie de reescrita da canção do protagonista do romance de Victor Hugo:

Antes de ser traduzida no ultimo quartel do século XX por Castro Alves, a canção posta por Victor Hugo na boca de Bug Jargal recebeu também uma versão para o português de Goncalves Dias, que a incluiu nos Últimos Cantos (1851). Leitor do poeta francês, o brasileiro já havia tomado versos seus por epigrafe em "O Vate" e em vários momentos de "O Soldado Espanhol", poemas incluídos nos Primeiros Cantos (1846) [sic]. Essa seria uma pista para 


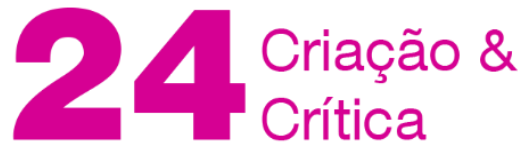

que se pudesse ler a sua "Canção do índio", também pertencente aos Primeiros Cantos, como uma reescrita da canção do herói negro de Hugo. Por outro lado, o tema da escravidão era caro ao poeta brasileiro e a condição de inferioridade pela cor da pele não era sua desconhecida: não se pode esquecer que nas suas origens estavam tanto o índio como possivelmente também o negro, e que foi provavelmente o facto de ser mestiço a causa de Ihe ter sido recusada a mão da mulher que amava. Ou, pelo menos, assim o entendeu Goncalves Dias. Numa espécie de resposta a negativa de seu pedido de casamento com Ana Amélia Ferreira do Vale e, ao mesmo tempo, numa glosa a sugestão de união de raças existente nos versos "junto ao dia / A noite o poente cria / E cria a aurora também, / Que mais luzentes belezas, / Mais doces que ambos tem.", que ele traduzira do romance de Victor Hugo (Dias, 1959: 454), escreveu "Tu não queres ligar-te comigo", poema no qual pergunta: "E tua casa no sangue tão clara, / Que eu me honrasse de unir-me contigo". (RIBEIRO, 2003, p. 96)

De fato, tal como o protagonista Pierrot em Bug-Jargal, o sujeito lírico de "Canto do Índio" é um rei que, em virtude do amor pela "virgem dos Cristãos", dispõe-se a "trocar a maça do poder por ferros". Assim, segundo Ribeiro, dar-se-ia uma reescrita do canto de BugJargal por meio da qual a ideia do surgimento de uma nova raça pela fusão do branco e do negro (substituído pelo índio brasileiro) seria adaptada aos propósitos estéticos e ideológicos do indianismo:
Ah! que não queiras tu vir ser rainha
Aqui dos meus irmãos, qual sou rei deles!
Escuta, ó Virgem dos Cristãos formosa.
Odeio tanto aos teus, como te adoro;
Mas queiras tu ser minha, que eu prometo
Vencer por teu amor meu ódio antigo,
Trocar a maça do poder por ferros
E ser, por te gozar, escravo deles.
(DIAS, 1998, p. 29)

Ribeiro vai além e levanta a hipótese de que Gonçalves Dias possa ter encontrado na "humildade de Bug-Jargal" (RIBEIRO, 2003, p.97) a posição de vassalagem recorrente em sua poesia indianista. Talvez seja difícil confirmar ou descartar de forma categórica tais hipóteses. É relevante, de qualquer forma, que em Bug-Jargal estejam presentes três dos temas principais de nossa literatura romântica: o tema do escravo, o tema do exílio e o mito de fundação nacional pela fusão de raças.

Assim, em um momento fulcral de formação da literatura brasileira, durante o qual "o hábito das versões poéticas vicejou de tal modo [...] que deixar de fazê-las era então motivo de geral estranheza" (TAVARES BASTOS, 1952, p. 5), a literatura traduzida parece ter tido 


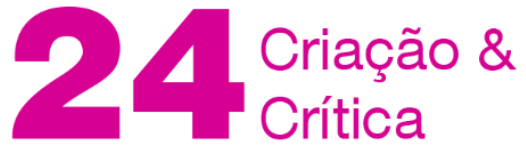

um papel importante na elaboração do "novo repertório" e na introdução de "facetas" (tanto princípios quanto elementos) na literatura local que não existiam anteriormente (EVENZOHAR, 2000, p. 193). Contrariamente à dicotomia que opõe de forma tão marcada literatura "original" e literatura "traduzida", a fronteira revela-se menos nítida na prática textual de autores proeminentes de nossa literatura oitocentista.

\section{Castro Alves, Gonçalves Dias e Bug-Jargal}

Sabe-se que tanto poetas-tradutores diletantes quanto autores consagrados (Gonçalves Dias, Álvares de Azevedo, Machado de Assis, Raimundo Correia, Casemiro de Abreu etc) cultivaram a prática das versões poéticas durante nosso século XIX. O caso BugJargal torna-se ainda mais interessante para nossa reflexão quando se sabe que Castro Alves, outro poeta-tradutor romântico de primeira grandeza, também produziu uma tradução em verso do mesmo excerto do romance de Hugo, incluída em Os Escravos como "Canto de Bug-Jargal" (leve nuance com relação ao título de Gonçalves Dias: "Canção de Bug-Jargal). Se houve quem interpretasse sob chave biográfica a apropriação do canto altivo do escravorei Bug-Jargal por Gonçalves Dias como "uma espécie de resposta à negativa de seu pedido de casamento com Ana Amélia Ferreira do Vale" por motivos raciais (RIBEIRO, 2003, p. 97), o texto é ressignificado ao ser inserido no verdadeiro libelo abolicionista que é o livro póstumo de Castro Alves. Assim, o canto do escravo-rei exilado é reforçado pelo coro dorido dos escravos epônimos da obra, porta-vozes de um poeta que pôde

[...]impor o escravo à sensibilidade burguesa, não como espoliado ou mártir; mas, o que é mais difícil, como ser igual aos demais no amor, no pranto, na maternidade, na cólera, na ternura. [...]Castro Alves se tornou o poeta por excelência do escravo ao Ihe dar, não só um brado de revolta, mas uma atmosfera de dignidade lírica, em que os seus sentimentos podiam encontrar amparo; ao garantir à sua dor, ao seu amor, a categoria reservada aos do branco, ou do índio literário. (CANDIDO, 1977, p. 277)

Não nos deteremos aqui na análise minuciosa das diferenças retórico-formais das traduções-poemas de Gonçalves Dias e Castro Alves. Bastem, nesse sentido, alguns breves comentários com base no cotejo do mesmo trecho traduzido por Bezerra de Menezes Neto, Castro Alves e Gonçalves Dias:

Mas, não sabes? Há muitas vezes no fundo do deserto um tufão ciumento da felicidade da fonte bem-amada; ele corre, e o ar, a areia misturam-se sob o voo das suas asas pesadas; envolve a árvore e a corrente no mesmo turbilhão de fogo; e a fonte seca, e a palmeira sente crispar-se-lhe sob o hálito da 


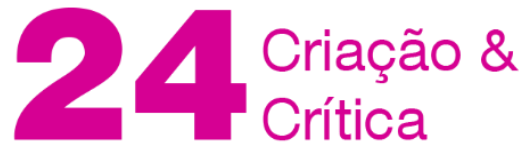

morte, o círculo verde das suas folhas, que tinham a majestade de uma coroa, e a graça de um penteado.[...] (HUGO, 1947, p.30-31)

Mas não sabes? - Do deserto

A tempestade valente

Corre às vezes de repente

Por acabar apressada

Com seu hálito de fogo

A palmeira, a fonte amada!

E a fonte já mais não corre!

Sente a verdura sumir-se

A palmeira, e contrair-se

A palma sua ao redor, Que de cabelos dava ares, De coroa tendo o esplendor![...]

(DIAS, 2016, p. 184)

Porém ... sabes? Às vezes há no fundo

Do deserto o uragã que tem ciúmes

Da fonte amada... e arroja-se e galopa.

$\mathrm{O}$ ar e a areia misturando turvos

Sob o voo pesado de suas asas.

Num turbilhão de fogo, árvore e fonte

Envolve... e seca a límpida vertente,

Sente a palmeira a um hálito de morte

Crespar-se o verde circ'lo da folhagem,

Que tinha a majestade de uma c'roa

E a graça de uma solta cabeleira.[...]

(ALVES, [S.a.], 56-57)

Para além das diferenças de estrofação, Castro Alves adota um verso decassílabo branco, que permite uma maior proximidade das estruturas sintáticas do texto prosaico. A redondilha maior rimada de Gonçalves Dias, por outro lado, impõe reelaborações mais drásticas, seja por supressões, seja por paráfrases condensadoras. Segundo Faleiros:

O texto de Castro Alves aproxima-se bastante do texto de Victor Hugo no que diz respeito ao sentido. Não há, no texto do poeta brasileiro, nenhuma elipse importante além da omissão da didascália, nenhum acréscimo lexical, nenhuma mudança importante de pontuação, ou seja, o tradutor procura uma, como se costuma dizer, fidelidade no nível semântico e produz uma dicção 


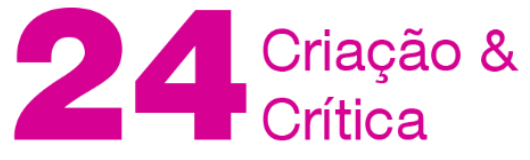

homóloga à de Victor Hugo, ainda que formalmente os textos distanciem-se. (FALEIROS, 2008, p.136).

A "retradução" (no sentido bermaniano) de Castro Alves e sua relação tanto com o excerto do Bug-Jargal de Hugo quanto com a tradução-poema de Gonçalves Dias que a antecede pode ser abordada à luz da teoria da hipertextualidade de Gérard Genette. Como se sabe, Genette chama hipertexto a "todo tipo texto derivado de um texto anterior por transformação simples [...] ou por transformação indireta"5 (1982, p. 16, tradução nossa). Destarte, a um hipertexto corresponderia (ao menos) um hipotexto, esquema que o autor assume ter sido inspirado pelo hipograma saussureano:

Entendo por isso [a hipertextualidade] toda relação que une um texto $B$ (que chamarei de hipertexto) a um texto A (que chamarei, é claro, hipotexto), sobre o qual ele se enxerta de uma maneira que não a do comentário. (GENETTE, 1982 , p. 13, tradução nossa) ${ }^{6}$

Assim, o romance Bug-Jargal pode ser considerado um hipotexto tanto do poematradução de Gonçalves Dias quanto do poema-tradução de Castro Alves. O texto de Gonçalves Dias, por sua vez, é tanto um hipertexto do romance quanto um hipotexto intermediário do poema-tradução de Castro Alves, cuja decisão de traduzir em verso o mesmo trecho em prosa que o poeta maranhense traduzira décadas antes parece carregado de um certo ímpeto emulativo que não se reduz a este caso. Com efeito, ecos gonçalvinos abundam ao longo dos poemas d'Os Escravos. Compare-se, por exemplo, o poema mítico de Gonçalves Dias "Agar no deserto" com a seção V de "O navio negreiro", que não só também alude à personagem bíblica como apresenta grandes semelhanças métricas e estróficas com o poema de Gonçalves Dias, lançando mão da mesma décima heptassilábica rimada, salvo pequenas diferenças na disposição das rimas (ABBACDEEDC em Gonçalves Dias, ABBACCDEED em Castro Alves):
O sol brilhante nascia
Sobre as tendas alvejantes
E n'outros pontos distantes
Combros d'areia feria,
Outrora leito d'um mar;
Esse caminho procura
Que nas ondas do deserto
Talvez ache por acerto

5 "[...]tout texte derivé d'un texte antérieur par transformation simple [...] ou par transformation indirecte". 6 "J'entends par là [l'Ohypertextualité] toute relation unissant um texte B (que j'appellerai hypertexte) à un texte antérieur A (que j'appellerai, bien sûr, hypotexte) sur lequel il se greffe d'une manière qui n'est pas celle du commentaire". 


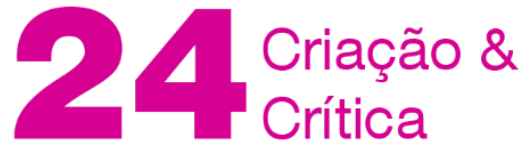

Pátria, abrigo, amor, ventura

A prole infausta d'Hagar.

(DIAS, 1998, p.122)

São mulheres desgraçadas, Como Agar o foi também.

Que sedentas, alquebradas,

De longe... bem longe vêm...

Trazendo com tíbios passos,

Filhos e algemas nos braços,

N'alma - lágrimas e fel...

Como Agar sofrendo tanto,

Que nem o leite de pranto

Têm que dar para Ismael.

(ALVES, [s.a.], p.90)

No final do poema de Gonçalves Dias, após desfalecer e ter sonhos proféticos sobre os feitos futuros de seus descendentes, Agar passa da condição de "serva" à de "rainha". Tratase de um Bug-Jargal ao contrário, que de rei se torna servo:

\author{
Vai, caminha, ó triste escrava, \\ Deus Senhor sobre ti vela; \\ Vai, caminha: a tua estrela \\ Nasce como um romper d'alva \\ Sobre os netos d'Ismael. \\ Esquece a sorte mesquinha \\ Que te vexa, esquece tudo \\ Deus Senhor é teu escudo: \\ Já não és serva, és rainha \\ D'outro reino Israel. (DIAS, 1998, p. 130)
}

Note-se, também, que a palmeira, índice da terra do exílio, também está presente na quinta seção do "Navio Negreiro":

Lá nas areias infindas,

Das palmeiras no país,

Nasceram crianças lindas,

Viveram moças gentis...

Passa um dia a caravana,

Quando a virgem na cabana

Cisma da noite nos véus ...

...Adeus, ó choça do monte,

...Adeus, palmeiras da fonte!... 


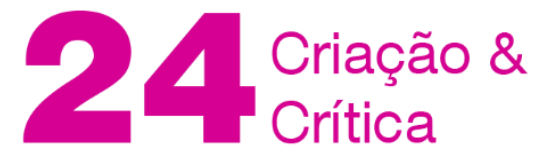

...Adeus, amores... adeus!... (ALVES, [s.a.], p.90)

Casos ainda mais evidentes de derivações textuais de Gonçalves Dias se dão em "Canção do Africano" e "Tirana" (parte de "Cachoeira de Paulo Afonso"), ambas estilizações de "Canção do exílio":

Minha Maria é morena,

Corno as tardes de verão;

Tem as tranças da palmeira

Quando sopra a viração.

Companheiros! o meu peito

Era um ninho sem senhor;

Hoje tem um passarinho

P'ra cantar o seu amor.

Trovadores da floresta!

Não digam a ninguém, não!...

Que Maria é a baunilha

Que me prende o coração.

Quando eu morrer só me enterrem

Junto às palmeiras do val,

Para eu pensar que é Maria

Que geme no taquaral...

(ALVES, [s.a.], p.133)

Minha terra é lá bem longe,

Das bandas de onde o sol vem;

Esta terra é mais bonita,

Mas à outra eu quero bem!

O sol faz lá tudo em fogo,

Faz em brasa toda a areia;

Ninguém sabe como é belo

Ver de tarde a papa-ceia!

Aquelas terras tão grandes, Tão compridas como o mar, Com suas poucas palmeiras

Dão vontade de pensar... 


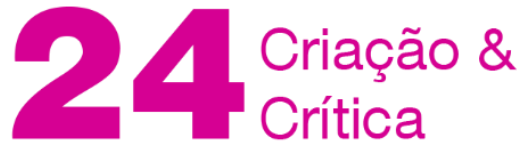

Lá todos vivem felizes,

Todos dançam no terreiro;

A gente lá não se vende

Como aqui, só por dinheiro

(ALVES, [s.a.], p.28)

Se assumirmos que a própria "Canção do exílio" parece se ligar a Bug-Jargal por um movimento de derivação plagiotrópica, o mesmo pode ser dito das estilizações castroalvinas do texto de Gonçalves Dias, que, ademais, são enunciadas explicitamente por figuras (ou porta-vozes) de escravos: em "Canção do africano", o "africano" anônimo; em "Tirana", a personagem Lucas. Quanto ao segundo caso, note-se, ainda, que o nome da amada de Lucas em "Cachoeira de Paulo Afonso" também é Maria, como no romance de Hugo. Terá o o escravo-rei de Bug-Jargal servido de modelo para o protagonista do trágico poema de Castro Alves? Talvez o canto altivo da personagem de Victor Hugo tenha mais ecos em Os Escravos do que se pense.

\section{Conclusão}

O caso das traduções parciais em verso de Bug-Jargal feitas por Gonçalves Dias e Castro Alves lança luz sobre uma série de questões importantes para a reflexão não só a respeito do papel da literatura traduzida no processo de formação da literatura brasileira, mas também a respeito da própria prática tradutória como uma das muitas formas de derivação textual que perpassam a história de todas as literaturas. Nesse sentido, pareceu-nos profícuo conjugar as três abordagens teóricas aludidas no começo do artigo, à luz das quais essas duas grandes questões podem ser pensadas. Se, por um lado, é pacífico em nossa historiografia literária que nossa literatura foi formada através de empréstimos ${ }^{7}$, por outro, talvez se subestime o papel da literatura "de segundo grau" (nos termos de Genette) na apropriação do repertório (nos termos de Even-Zohar) aproveitado nas produções "originais", conforme demonstra a provável apropriação plagiotrópica (nos termos de Campos) que Gonçalves Dias fez de Victor Hugo em "Canção do exílio". Para tal reflexão, é mister não perder de vista que literatura "traduzida" e literatura "original" muitas vezes se confundem em nossa produção poética do século XIX, conforme demonstra Faleiros (2012) no estudo citado sobre versões poéticas brasileiras de Mallarmé, razão pela qual nos pareceram profícuas as abordagens de Gérard Genette e Haroldo de Campos, que relativizam a oposição entre literatura original e literatura traduzida.

7 "Foi, portanto, por meio de empréstimos ininterruptos que nos formamos, definimos a nossa diferença relativa e conquistamos consciência própria. Os mecanismos de adaptação, as maneiras pelas quais as influências foram definidas e incorporadas é que constituem a 'originalidade', que no caso é a maneira de incluir em contexto novo os elementos que vêm de outro" (CANDIDO, 2003, p. 92). 


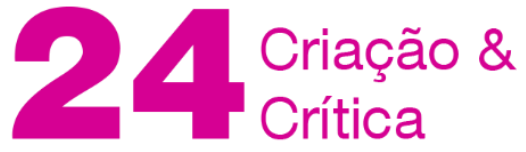

Se o movimento plagiotrópico descrito por Campos é próprio da literatura como um todo, parece-nos que esse movimento acentua-se em períodos formativos de sistemas literários jovens, o que vem ao encontro das propostas de Even-Zohar a respeito. Além disso, deve-se também lembrar que nos formamos por afluxo de elementos materiais e simbólicos exógenos para muito além da literatura, de forma que nossa vocação "paródica" (seja no sentido estrito da subversão cômica, seja no sentido lato do "canto paralelo" utilizado por Haroldo de Campos) extrapola o âmbito meramente textual. "Inventada pela Europa como um mundo ao lado, a América sempre teve essa tendência, voluntária ou involuntária, de ser a paródia da Europa." (PERRONE-MOYSÉS, 2007, p.49) A consciência de tal condição, no entanto, bem como de suas contradições e desajustes, não deve acarretar em uma perpétua atitude melancólica de autodepreciação. Assim, os deslocamentos produzidos pelo eventual desajuste entre as formas importadas e nossas características não devem ser pensadas como traços de inaptidão ou inferioridade, mas como resoluções formais engenhosas e inovadoras dentro de condições particulares, como são as traduções-poemas de Gonçalves Dias, Castro Alves e outras produções de literatura "original" ou "traduzida".

\section{Referências}

CAMPOS, H. Metalinguagem \& outras metas: ensaios de teoria e crítica literária. São Paulo: Perspectiva, 2006. . Deus e o Diabo no Fausto de Goethe. São Paulo: Perspectiva, 1981.

CANDIDO, A. Formação da literatura brasileira: momentos decisivos. São Paulo: Edusp, 1977. . O romantismo no Brasil. São Paulo: Humanitas, 2003.

DIAS, A. Primeiros cantos. Belo Horizonte: Autêntica, 1998.

. Últimos cantos. Londrina: Redacional, 2016.

EVEN-ZOHAR, I. "The position of translated literature within the literary polysystem". In: VENUTI, L. (Ed.). The Translation Studies Reader. New York: Routledge, 2000. Capítulo 15, p.192-197.

. Em busca de Castro Alves tradutor. In: GUERINI, A.; TORRES, M.; COSTA, W. (Orgs.). Literatura traduzida e literatura nacional. Rio de Janeiro: 7Letras, 2008. p. 121-132.

FALEIROS, A. Três Mallarmés: traduções brasileiras. Aletria, Belo Horizonte, v. 22, n. 1, p. 17-31, 2012.

GENETTE, G. Palimpsestes: la littérature au second degré. Paris: Seuil, 1982.

HUGO, V. Bug-Jargal. Paris: Ollendorf, 1910.

. Bug-Jargal: o libertador negro. Tradução de Adolfo de Bezerra de Menezes Neto.

Salvador: Livraria Progresso Editora, 1947.

PERRONE-MOISÉS, L. Vira e mexe nacionalismo: paradoxos do nacionalismo literário. São Paulo: Companhia das Letras, 2007. 


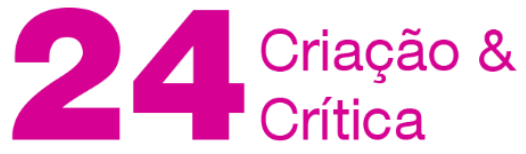

RIBEIRO, M. A aurora e o crepúsculo: a recepção de Bug-Jargal e a questão racial no Brasil. Biblos, Coimbra, v. 1, p. 87-110, 2003.

TAVARES BASTOS, C. Versões poéticas brasileiras de Victor Hugo. Petrópolis: Artes Gráficas, 1952.

Recebido em: 23/04/2019 Aceito em: 26/05/2019

Referência eletrônica: PAMBOUKIAN, Mateus Roman. O Caso Bug-Jargal: Tradução, transposição e hipertextualidade no romantismo brasileiro. Criação \& Crítica, n. 24, p., out. 2019. Disponível em: <http://revistas.usp.br/criacaoecritica>. Acesso em: dd mmm. aaaa. 